\title{
The effect of bile acids on the growth and global gene expression profiles in Akkermansia muciniphila
}

\author{
Tatsuro Hagi $^{1,2}$ (D) Sharon Y. Geerlings ${ }^{1} \cdot$ Bart Nijsse $^{3} \cdot$ Clara Belzer $^{1}$ \\ Received: 22 May 2020 / Revised: 11 October 2020 / Accepted: 25 October 2020 / Published online: 7 November 2020 \\ (C) The Author(s) 2020
}

\begin{abstract}
Akkermansia muciniphila is a prominent member of the gut microbiota and the organism gets exposed to bile acids within this niche. Several gut bacteria have bile response genes to metabolize bile acids or an ability to change their membrane structure to prevent membrane damage from bile acids. To understand the response to bile acids and how A. muciniphila can persist in the gut, we studied the effect of bile acids and individual bile salts on growth. In addition, the change in gene expression under oxbile condition was studied. The growth of $A$. muciniphila was inhibited by ox-bile and the bile salts mixture. Individual bile salts have differential effects on the growth. Although most bile salts inhibited the growth of $A$. muciniphila, an increased growth was observed under culture conditions with sodium deoxycholate. Zaragozic acid A, which is a squalene synthase inhibitor leading to changes in the membrane structure, increased the susceptibility of A. muciniphila to bile acids. Transcriptome analysis showed that gene clusters associated with an ABC transporter and RND transporter were upregulated in the presence of ox-bile. In contrast, a gene cluster containing a potassium transporter was downregulated. Membrane transporter inhibitors also decreased the tolerance to bile acids of A. muciniphila. Our results indicated that membrane transporters and the squalene-associated membrane structure could be major bile response systems required for bile tolerance in A. muciniphila.
\end{abstract}

\section{Key points}

- The growth of Akkermansia muciniphila was inhibited by most bile salts.

- Sodium deoxycholate increased the growth of A. muciniphila.

- The genes encoding transporters and hopanoid synthesis were upregulated by ox-bile.

- The inhibitors of transporters and hopanoid synthesis reduced ox-bile tolerance.

Keywords Akkermansia muciniphila · Bile acids · Transcriptome

Supplementary Information The online version contains supplementary material available at https://doi.org/10.1007/s00253-02010976-3.

\footnotetext{
Tatsuro Hagi

thagi@affrc.go.jp

$\triangle$ Clara Belzer

clara.belzer@wur.nl

1 Laboratory of Microbiology, Wageningen University and Research, 6708 WE Wageningen, The Netherlands

2 Institute of Livestock and Grassland Science, National Agriculture and Food Research Organization (NARO), 2 Ikenodai, Tsukuba, 305-0901 Ibaraki, Japan

3 Laboratory of Systems and Synthetic Biology, Wageningen University and Research, 6708 WE Wageningen, The Netherlands
}

\section{Introduction}

The human gut microbiome study has revealed the biodiversity of gut bacteria in healthy individuals or individuals with human (Consortium HMP 2012). A part of the gut bacteria plays an important role in human health (Flint et al. 2012) and interacts with host immunity and nutrition (Rowland et al. 2018; Thaiss et al. 2016). Akkermansia muciniphila is an attractive commensal gut bacteria to study because of its probiotic effect such as improvement of obesity and metabolic disorders and modulation of host immunity (Ansaldo et al. 2019; Everard et al. 2013). A. muciniphila resides in the colonic mucus layer where this bacterium degrades mucin, using it as carbon and nitrogen source (Derrien et al. 2004). The mucus layer, which is mainly composed of glycoproteins with 
specific $O$-linked glycans, is a major host defense system. Other commensal and pathogenic bacteria have adhesive molecules to mucus for gut colonization (Sicard et al. 2017). Some factors such as intestinal $\mathrm{pH}$, oxygen, and bile acids also influence microbial composition in the colon (Flint et al. 2012). Oxygen generated by epithelial cells could cause damage to strict anaerobic gut bacteria. In addition to a nutritional advantage based on mucin utilization, A. muciniphila also has an oxygen consumption system using the cytochrome bd complex (Ouwerkerk et al. 2016). A. muciniphila takes an advantage of this unique system to protect the cell from oxygen damage and thereby persists in the gut. Recently, it is reported that A. muciniphila needs GlcNAc for growth in the absence of mucus, and a defined medium without mucin, which supports understanding physiological properties of $A$. muciniphila, has been established (van der Ark et al. 2018).

The interaction between bile acids and gut bacteria is extremely complex. Bile acids consist of primary bile acids produced in the liver such as cholic acid (CA) and chenodeoxycholic acid (CDCA) and secondary bile acids generated by gut bacteria such as deoxycholic acid (DCA) and lithocholic acid (LCA) (Wahlstrom et al. 2016). There is a strong relationship between bile acids and human health (Wahlstrom et al. 2016). Secondary bile acids can cause colitis (Saracut et al. 2015). On the other hand, secondary bile acids can inhibit the growth of Clostridium difficile causing diarrhea and colitis in mice (Studer et al. 2016). The balance of bile acids and microbiota is also important for our health because dysbiosis leading to secondary bile acid deficiency could promote intestinal inflammation (Sinha et al. 2020). To clear the complex metabolism of bile acids, the interaction of bile acid-gut bacteria axis and its impacts on human health and disease have been widely studied (Staley et al. 2017; Wahlstrom et al. 2016).

A. muciniphila is one of the most related commensal gut bacteria to bile acid-host metabolism axis. Van den Bossche et al. (2017) reported that the administration of ursodeoxycholic acid, which is a small amount in the human intestine, could increase a number of A. muciniphila and improve colitis in mice. The increase of bile acids (especially, cholic acid) could reduce the population of A. muciniphila in the high-fat dietinduced obese mice (Zheng et al. 2017), and this study indicates A. muciniphila may be regulated by bile acids. The investigation of cross talk between A. muciniphila and bile acids is important to understand how A. muciniphila can survive in the gut environment and contribute to human health.

Bile acids could damage the bacterial cell membrane and thereby cause cell death (Kurdi et al. 2006). Therefore, bile acid tolerance of probiotic bacteria has been widely investigated since bile acid tolerance leading to survivability in the gut is one of the probiotic criteria. Bile acid metabolism in Lactobacillus and Bifidobacterium has been reviewed (Ruiz et al. 2013). Changes in membrane components such as isoprenoid and peptidoglycan are related to bile acid tolerance in
Gram-positive bacteria such as Listeria and lactic acid bacteria (Begley et al. 2002; Hagi et al. 2013; Hamon et al. 2012). In Gram-negative bacteria, hopanoids (a group of isoprenoids) are required for bile acid resistance in Rhodopseudomonas palustris and symbiosis with plant in Bradyrhizobium sp. (Hamon et al. 2012; Silipo et al. 2014; Welander et al. 2009). Isoprenoids are one of the most important factors for bile acid tolerance in both Gram-positive and Gram-negative bacteria. In addition, bile acid-inducible (bai) genes encoding bile transporters and dehydroxylation enzymes are also mainly related to bile acid metabolism and tolerance in the gut bacteria (Vital et al. 2019). Although a gene for a bile acid:sodium symporter (Amuc_0139) is found in the genome of A. muciniphila (NC_010655), the dynamics and gene expression of A. muciniphila in response to bile acids are unknown.

To clear how A. muciniphila interacts with bile acids, in this study, the growth of A. muciniphila under bile acids and individual bile salt condition including main bile acids such as cholic acid and deoxycholic acid was investigated. In addition, the response to bile acids was investigated by transcriptome analysis. Here, we show that the different effects of bile salts on the growth of A. muciniphila and change in gene expression have grown under bile acid condition. Furthermore, the effect of a squalene synthase inhibitor and membrane transporter inhibitors on bile acid tolerance in $A$. muciniphila is reported herein.

\section{Materials and methods}

\section{A. muciniphila growth condition}

A. muciniphila MucT (DSM 22959) was anaerobically grown in $10 \mathrm{~mL}$ basal medium (Derrien et al. 2004) supplemented with $20 \mathrm{~g} / \mathrm{L}$ tryptone, $4 \mathrm{~g} / \mathrm{L}$ L-threonine, $2.75 \mathrm{~g} / \mathrm{L}$ GlcNAc, and $2.5 \mathrm{~g} / \mathrm{L}$ glucose monohydrate at $37^{\circ} \mathrm{C}$ (van der Ark et al. 2017). All components in modified basal medium (mBM) were purchased from Sigma-Aldrich (St. Louis, MO, USA), except for tryptone (Oxoid Ltd., Basingstoke, Hampshire, England).

Bile extracts and individual bile salts were purchased from Sigma-Aldrich: bile extract porcine (bile porcine: B8631), ox-bile for microbiology (ox-bile; 70,168), bile salts for microbiology (bile salts mixture: mixture of sodium cholate and sodium deoxycholate; B8756), sodium cholate (CA; 27028), glycocholic acid sodium (GCA; G7132), sodium deoxycholate (DCA; D6750), sodium glycochenodeoxycholate (GCDCA; G0759), sodium glycodeoxycholate (GDCA; G9910), sodium taurocholate hydrate (TCA; 86,339), sodium taurodeoxycholate hydrate (TDCA; T0557), chenodeoxycholic acid sodium (CDCA; C8261), and 
taurochenodeoxycholic acid sodium (TCDCA; T6260). For stock solutions, ox-bile and bile salts mixture were dissolved in $\mathrm{mBM}$, and bile porcine was dissolved in distilled water at a concentration of $10 \%(\mathrm{wt} / \mathrm{vol})$. Stock solutions of each individual bile salts were prepared in a medium of $100 \mathrm{mM}$ (wt/vol). Stock solutions except bile porcine were sterilized by $0.22-\mu \mathrm{m}$-pore polyethersulfone membrane filter (mdi Membrane Technologies; Harrisburgh, PA, USA) before use. The bile porcine was adjusted to $\mathrm{pH} 7.0$ by $\mathrm{NaOH}$ and autoclaved. Stock solutions were added to culture media in different concentrations.

One milliliter of a fully grown pre-culture containing A. muciniphila in $\mathrm{mBM}$ was inoculated into $10 \mathrm{~mL}$ of mBM supplemented with different concentrations of bile extract $\mathrm{M}$ and individual bile salts. To test for the inhibition of isoprenoid (squalene) production, zaragozic acid A (ZA; Santa Cruz Biotechnology, Santa Cruz, CA, USA) was added to the culture containing $0.1 \%$ ox-bile, bile salts mixture, and bile porcine. The final concentration of ZA in these cultures was $15 \mu \mathrm{M}$. After incubation at $37{ }^{\circ} \mathrm{C}$ for $48 \mathrm{~h}$, the optical density $\left(\mathrm{OD}_{600}\right)$ was measured as reported previously (Ouwerkerk et al. 2016). For the ZA-treated test, mBM with $70 \%$ ethanol $(25.9 \mu \mathrm{L} / 10 \mathrm{~mL} \mathrm{mBM})$ was used as control because ZA was diluted in $70 \%$ ethanol. These experiments were performed in triplicate $(n=3)$. The statistical analysis was performed by Dunnett's test or paired $t$ test. For quality control, the cultures were visualized under the microscope after growth following $48 \mathrm{~h}$ of incubation.

\section{RNA extraction}

Two milliliters of a fully grown pre-culture containing $A$. muciniphila in $\mathrm{mBM}$ was inoculated into $10 \mathrm{~mL} \mathrm{mBM}$ supplemented with $0.1 \%$ ox-bile. Cell cultures were grown in triplicate under control and ox-bile conditions. After incubation at $37^{\circ} \mathrm{C}, 7 \mathrm{~mL}$ of cell culture $\left(\mathrm{OD}_{600}=\sim\right.$ 1.0) was mixed with $14 \mathrm{~mL}$ of RNAprotect Bacteria Reagent (Qiagen GmbH, Hilden, Germany). After centrifugation at $8000 \times g$ for $10 \mathrm{~min}$, the cell pellets were dissolved in $200 \mu \mathrm{L}$ of TE buffer containing lysozyme $(15 \mathrm{mg} / \mathrm{mL})$, proteinase $\mathrm{K}(0.1 \mathrm{mg} / \mathrm{mL})$, and mutanolysin $(10 \mathrm{U} / \mathrm{mL})$. After incubation for $40 \mathrm{~min}$ at room temperature, RTL buffer was added and the RNA extraction with DNase treatment was performed using a RNeasy mini kit and RNase-Free DNase Set according to the manufacturer's instructions. RNA and DNA concentrations were measured using the Qubit RNA BR assay kit and the Qubit DNA BR assay kit, respectively (Thermo Fisher Scientific, Waltham, Massachusetts, USA). The quality of the isolated RNA was assessed using a Qsep100 (BiOptic, La Canada Flintridge, CA, USA).

\section{Transcriptome analysis}

RNA samples (biological triplicates in each of two conditions) were run as follows. RNA-seq (2G raw data per sample) was performed by Novogen (Cambridge Science Park, Cambridge, UK) using HiSeq platforms with paired-end $150 \mathrm{bp}$. Illumina reads have been trimmed for low quality and adapters with fastp (v0.20.0) (Chen et al. 2018) using default settings. rRNA sequences have been removed with bbduk (v38.35) (https://sourceforge.net/projects/bbmap/) using the following parameters: $k=31$ and ref. $=$ riboKmers. fa.gz. Transcripts from the reference strain of $A$. muciniphila (GCF_000020225.1) have been quantified with Kallisto (v0.46.0) (Bray et al. 2016) with a bootstrap value of 100 . Transcript abundances were imported using the R/Bioconductor package tximport for differential expression analysis (Soneson et al. 2015). Differential expression analysis has been performed with DESeq2 using the biological replicates for each condition and padj (adjusted $p$ values) was calculated using the procedure of Benjamini and Hochberg to avoid false-positive results (Bufe et al. 2019; Love et al. 2014). Differences obtained at the $p$ adj $<0.05$ level $(n=$ 3) were considered significant.

\section{Membrane transporter inhibitor test}

Two membrane transporter inhibitors, orthovanadate (SigmaAldrich, S6508; St. Louis, MO, USA) and Phe-Arg $\beta$ naphthylamide dihydrochloride (PA $\beta N$; Sigma-Aldrich, P4157) known as ABC transporter inhibitor and RND-type transporter inhibitor (Lin and Martinez 2006; Ricci and Piddock 2003), were used for transporter inhibition test. Orthovanadate was dissolved with distilled water and the $\mathrm{pH}$ was adjusted to 7.5 ( $200 \mathrm{mM}$ stock solution). The stock solution was incubated at $90{ }^{\circ} \mathrm{C}$ until translucent. $\mathrm{PA} \beta \mathrm{N}$ was dissolved in distilled water $(0.5 \mathrm{mg} / \mathrm{mL}$ stock solution $)$. These stock solutions were sterilized using a $0.22-\mu \mathrm{m}$-pore filter. Two hundred microliters of orthovanadate and $100 \mu \mathrm{L}$ of PA $\beta N$ were added to medium supplemented with $0.1 \%$ oxbile (final concentrations of inhibitors are $4 \mathrm{mM}$ and $5 \mu \mathrm{g} / \mathrm{mL}$, respectively). The growth of $A$. muciniphila was monitored by $\mathrm{OD}_{600}$ measurements.

\section{Accession number}

The RNA-seq data were deposited into the NCBI Sequence Read Archive (SRA) with the BioProject ID PRJNA639650. The BioSample accession numbers "SAMN15311471 to S AMN 15311473 " and "S AMN 15312138 to SAMN15312140" correspond to the data under control and bile acid conditions, respectively. 


\section{Results}

\section{The effect of bile acids on the growth of $A$. muciniphila}

To test the tolerance of $A$. muciniphila against bile acids, bile salts mixture and major two types of bile acids derived from bovine and porcine were selected (Begley et al. 2002). A. muciniphila was cultured in the presence of ox-bile, bile salts mixture, and bile porcine at different concentrations (final conc. 0.1-, 0.2-, and 0.5\%). After incubation for $48 \mathrm{~h}$, the growth of A. muciniphila was significantly inhibited at the concentration of $0.2 \%$ and $0.5 \%$ ox-bile and bile salts mixture (Fig. 1). The growth tended to decrease in cultures containing $0.1 \%$ ox-bile (significantly decreased at the 24 -h time point, data not shown). On the other hand, the growth of $A$. muciniphila significantly increased at bile salt concentrations of $0.1 \%$. Transcriptome analysis and inhibition test of isoprenoid production and membrane transporters were performed at the concentration of $0.1 \%$ ox-bile because ox-bile inhibited the growth of $A$. muciniphila in a dose-dependent manner and $0.1 \%$ ox-bile has a weak inhibitory effect. In addition, the cultures with a concentration of $0.1 \%$ bile acids could influence gene expression of Lactobacillus plantarum WCFS1 and is within the range of physiological concentration in the gastrointestinal tract (Bron et al. 2004; Hu et al. 2018).

\section{The effect of individual bile salts on the growth of $A$. muciniphila}

To investigate the effect of individual bile salts, the growth of A. muciniphila cultured in the presence of 9 bile salts at the different concentrations was assessed (final conc. 1 and $5 \mathrm{mM}$ ). Six bile salts (glycocholic acid sodium: GCA,

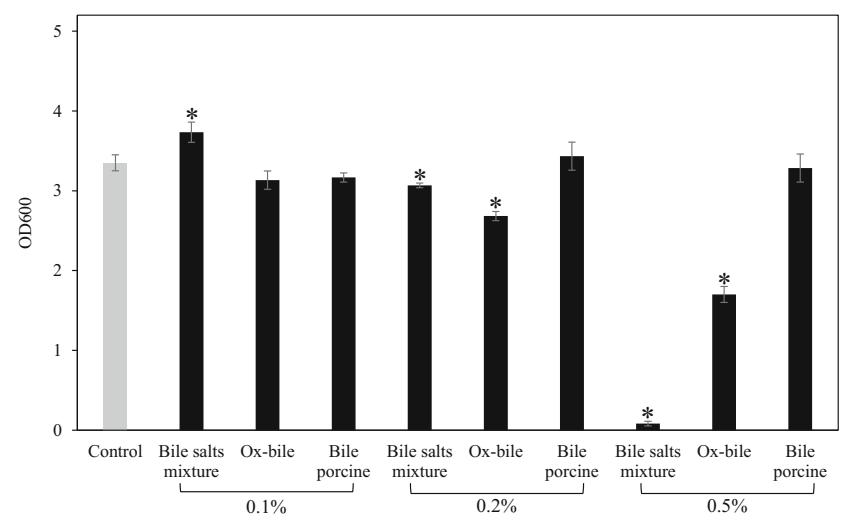

Fig. 1 The effect of bile extracts and bile salts mixture on the growth of $A$. muciniphila. A. muciniphila was cultured in the presence of ox-bile, bile salts mixture, and bile porcine $(0.1 \% ; 0.2 \% ; 0.5 \%)$. After incubation at $37{ }^{\circ} \mathrm{C}$ for $48 \mathrm{~h}$, the optical density was measured $\left(\mathrm{OD}_{600}\right)$. These experiments were performed in triplicate $(n=3)$. ${ }^{*}$ Significant difference between control (no treatment with bile acids) and bile-treated groups, Dunnett's test, $p<0.05$
GDCA; sodium glycochenodeoxycholate: GCDCA; sodium taurodeoxycholate hydrate: TDCA; taurochenodeoxycholic acid sodium: TCDCA and CA) were found to inhibit the growth of A. muciniphila (Fig. 2). Only two of these, GDCA and TDCA, inhibited the growth at a final concentration of $1 \mathrm{mM}$. There was no significant difference between control and groups treated with other bile salts (TCA and CDCA). Interestingly, the growth of A. muciniphila significantly increased in the presence of DCA, which is a secondary bile salt, although glycine-conjugated DCA (GDCA) showed the strong inhibition of the growth.

\section{The effect of squalene synthase inhibitor (zaragozic acid $\mathrm{A}$ ) on the bile acid tolerance of $A$. muciniphila}

Kyoto Encyclopedia of Genes and Genomes (https:// www.genome.jp/kegg/) shows A. muciniphila has isoprenoid biosynthesis genes leading to squalene (EC: 2.5.1.21, AMUC_RS02040) and hopanoid (sterol) biosynthesis (EC:5.4.99.17 and EC:4.2.1.129, AMUC_ RS02875). In the genome database, 5 genes encoding terpene cyclase/mutase family protein (AMUC RS06010, AMUC_RS06015, AMUC_RS03775, AMUC_RS03780, and AMUC_RS10605) as well as AMUC_RS02875 exist. ZA, which can inhibit bacterial squalene synthase (Rivas-Marin et al. 2019), was used to investigate the relationship between squalene (precursor of hopanoid) and bile acid tolerance. As a result, the growth of A. muciniphila cultured with $0.1 \%$ bile salts mixture and ox-bile was significantly inhibited upon the addition of ZA (Fig. 3). There is no significant difference in cultures supplemented with $0.1 \%$ bile porcine. ZA did not affect the growth of A. muciniphila cultured without ox-bile (data not shown).

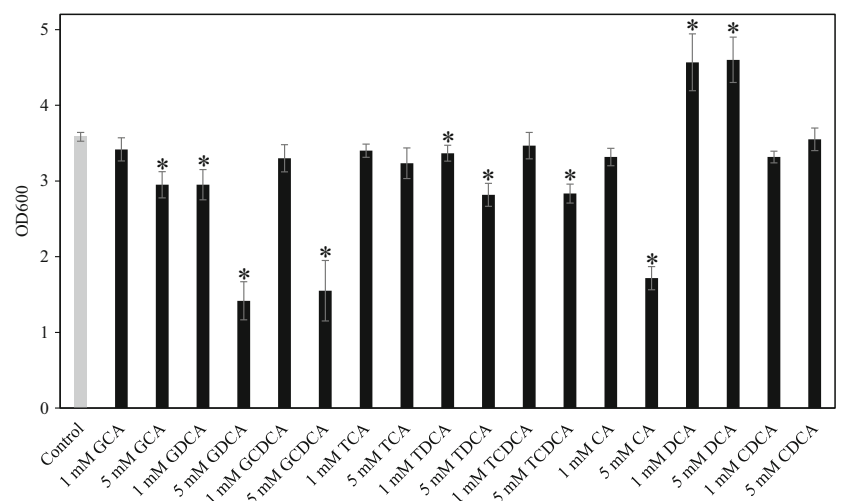

Fig. 2 The effect of individual bile salts on the growth of A. muciniphila. A. muciniphila was cultured in the presence of individual bile salts at different concentrations (final conc. 1 and $5 \mathrm{mM}$ ). After incubation at $37{ }^{\circ} \mathrm{C}$ for $48 \mathrm{~h}$, the optical density was measured $\left(\mathrm{OD}_{600}\right)$. These experiments were performed in triplicate $(n=3)$. *Significant difference between control (no treatment with bile salts) and individual bile salttreated groups, Dunnett's test, $p<0.05$ 


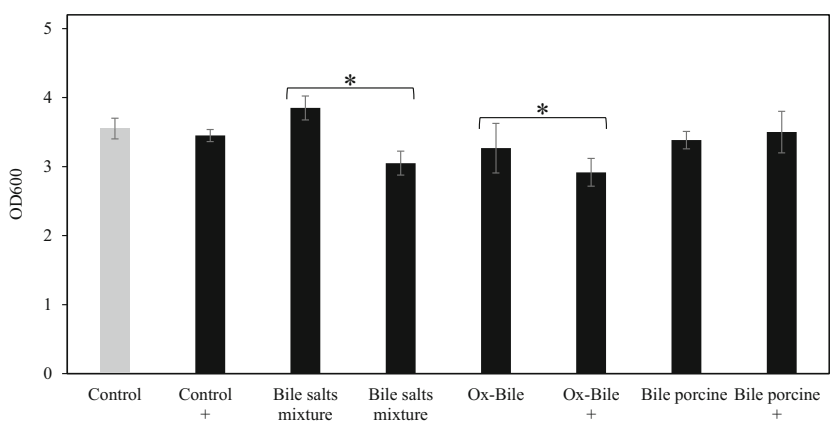

Fig. 3 The effect of zaragozic acid A on the tolerance of A. muciniphila against bile extracts and bile salts mixture. A. muciniphila was cultured in medium containing $0.1 \%$ ox-bile, bile salts mixture, and bile porcine supplemented with or without zaragozic acid A. After incubation at $37{ }^{\circ} \mathrm{C}$ for $48 \mathrm{~h}$, the optical density was measured $\left(\mathrm{OD}_{600}\right)$. These experiments were performed in triplicate $(n=3)$. Control means no treatment with bile acids. ${ }^{+}$Treatment with zaragozic acid A (final concentration $15 \mu \mathrm{M}) *$ Paired $t$ test, $p<0.05$

\section{Change in gene expression in response to ox-bile}

The change in gene expression in cultures with and without $0.1 \%$ ox-bile was determined by DESeq and visualized using a volcano plot (Fig. 4). There were 1008 significant differentially expressed genes (green and red, $p$ adj $<0.05$ ) which contained 454 upregulated genes and 554 downregulated genes (all genes are listed in Supplementary Table S1).
Figure 4 (red point) and Table 1 show the upregulated and downregulated genes under ox-bile condition ( $p$ adj $<0.05, \log 2$ fold changes with cut-off at $<-0.585$ and $>0.585$ ). Thirtyeight genes were upregulated in the cultures supplemented with ox-bile (Table 1). The gene expression of the $\mathrm{ABC}$ transporter systems (AMUC_RS07350, AMUC_RS00025, AMUC_RS07355, and AMUC_RS07345) and ABC transporter-associated HlyD family efflux transporter periplasmic adaptor subunit (AMUC_RS07360) was significantly upregulated. Four genes (AMUC_RS07345 to AMUC_RS07360) are considered to form a gene cluster of $\mathrm{ABC}$ transporter-associated genes (Fig. 5). Efflux RND transporter periplasmic adaptor subunit (AMUC_RS10890) and two genes, downstream of AMUC_RS10890, were slightly but significantly upregulated ( $p a d j<0.05, \log 2$ fold change of AMUC_RS10895 and AMUC_RS10900 was 0.495 and 0.396, respectively, Supplementary Table S1). In addition, PEP-CTERM domain protein (AMUC_RS10910), which is a membrane protein, was also upregulated. The DnaK gene (AMUC_RS07510), which is the stress response gene known to encode a major stress-inducible chaperone (LaRossa and Van Dyk 1991), was also significantly upregulated. Concerning hopanoid biosynthesis-related genes, four genes encoding terpene cyclase/mutase family protein (AMUC_RS03775, AMUC_RS06010, AMUC_RS06015, and AM UC_RS03775) were slightly but significantly
Fig. 4 Volcano plot of the ox-bile versus normal condition. Green and red points mean significant change in gene expression under ox-bile condition ( $p$ adj $<0.05$ ). The red point means $\log 2$ fold changes cut-off $<-0.585$ and $>$ 0.585 . Volcano plot was described by R 3.6.1. The data corresponding to significant differences in gene expression under ox-bile conditions can be found in Supplemental Table S1. These experiments were performed in triplicate $(n=3)$

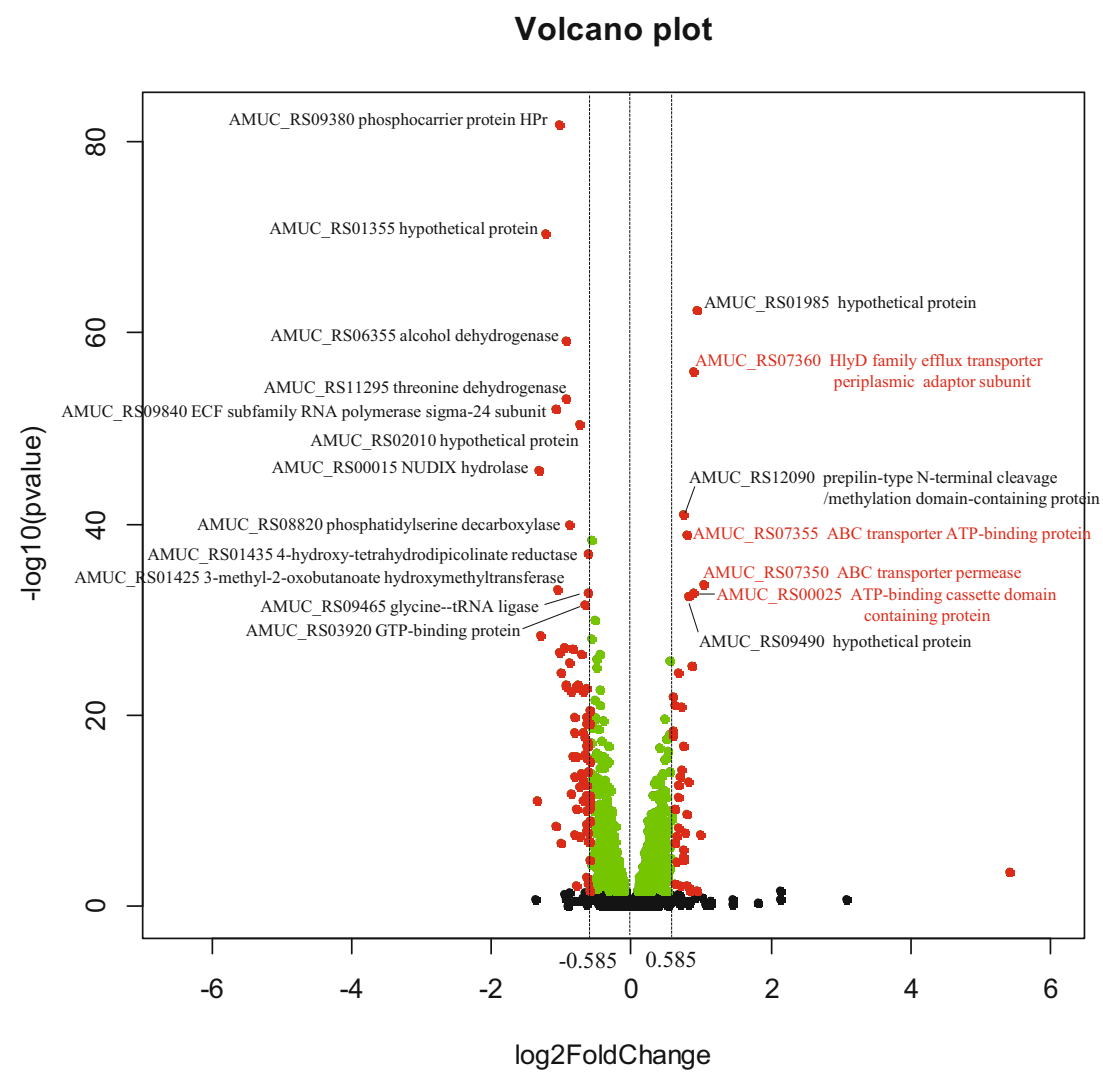


Table 1 Differential gene expression in response to ox-bile

\begin{tabular}{lllll}
\hline Locus_tag & $\begin{array}{l}\text { Log2 fold } \\
\text { change }\end{array}$ & padj $\quad$ ID & Product & Protein_ID \\
\hline
\end{tabular}

\begin{tabular}{|c|c|c|c|c|c|}
\hline \multicolumn{6}{|l|}{ Upregulated genes } \\
\hline AMUC_RS04540 & 5.426 & 0.00106 & gene905 & Hypothetical protein & WP_042447787.1 \\
\hline AMUC_RS07350 & 1.032 & $3.12 \mathrm{E}-32$ & gene1461 & $\mathrm{ABC}$ transporter permease & WP_012420419.1 \\
\hline AMUC_RS04835 & 0.981 & $2.80 \mathrm{E}-07$ & gene964 & Hypothetical protein & WP_042447818.1 \\
\hline AMUC_RS01985 & 0.938 & $2.64 \mathrm{E}-60$ & gene395 & Hypothetical protein & WP_012419409.1 \\
\hline AMUC_RS00145 & 0.930 & 0.044701 & gene28 & Hypothetical protein & WP_042447393.1 \\
\hline AMUC_RS00025 & 0.901 & $2.25 \mathrm{E}-31$ & gene4 & ATP-binding cassette domain-containing protein & WP_012419065.1 \\
\hline AMUC_RS07360 & 0.901 & $5.31 \mathrm{E}-54$ & gene1463 & HlyD family efflux transporter periplasmic adaptor subunit & WP_012420421.1 \\
\hline AMUC_RS00090 & 0.865 & $4.54 \mathrm{E}-24$ & gene17 & Hypothetical protein & WP_042447385.1 \\
\hline AMUC_RS11530 & 0.838 & 0.040573 & gene 2300 & Hypothetical protein & WP_012421183.1 \\
\hline AMUC_RS02315 & 0.833 & 0.044265 & gene461 & Hypothetical protein & WP_042447591.1 \\
\hline AMUC_RS09490 & 0.809 & $3.43 \mathrm{E}-31$ & gene 1890 & Hypothetical protein & WP_012420811.1 \\
\hline AMUC_RS03250 & 0.809 & $1.76 \mathrm{E}-12$ & gene648 & Phospholipid/glycerol acyltransferase & WP_012419647.1 \\
\hline AMUC_RS03405 & 0.805 & $2.22 \mathrm{E}-09$ & gene679 & Peptidase M60 & WP_012419679.1 \\
\hline AMUC_RS07355 & 0.793 & $3.10 \mathrm{E}-37$ & gene1462 & $\mathrm{ABC}$ transporter ATP-binding protein & WP_012420420.1 \\
\hline AMUC_RS03410 & 0.792 & 0.019798 & gene680 & Hypothetical protein & WP_042447676.1 \\
\hline AMUC_RS04655 & 0.770 & $2.01 \mathrm{E}-07$ & gene928 & Hypothetical protein & \\
\hline AMUC_RS12090 & 0.749 & $2.69 \mathrm{E}-39$ & gene 1685 & $\begin{array}{l}\text { Prepilin-type N-terminal cleavage/methylation domain-containing } \\
\text { protein }\end{array}$ & WP_012420618.1 \\
\hline AMUC_RS04775 & 0.749 & $7.39 \mathrm{E}-05$ & gene 952 & Hypothetical protein & WP_042447805.1 \\
\hline AMUC_RS02165 & 0.743 & $5.90 \mathrm{E}-16$ & gene431 & tRNA pseudouridine synthase A & WP_012419443.1 \\
\hline AMUC_RS04970 & 0.736 & $3.86 \mathrm{E}-05$ & gene992 & Glycosyl hydrolase family 109 protein 2 & WP_012419967.1 \\
\hline AMUC_RS07595 & 0.735 & $8.01 \mathrm{E}-06$ & gene1509 & Hypothetical protein & WP_042448077.1 \\
\hline AMUC_RS07345 & 0.731 & $5.04 \mathrm{E}-20$ & gene1460 & Antibiotic $\mathrm{ABC}$ transporter permease & WP_012420418.1 \\
\hline AMUC_RS08910 & 0.729 & $1.17 \mathrm{E}-13$ & gene1774 & Hypothetical protein & WP_042448215.1 \\
\hline AMUC_RS05455 & 0.707 & $5.40 \mathrm{E}-13$ & gene 1087 & Hypothetical protein & WP_012420058.1 \\
\hline AMUC_RS05825 & 0.690 & 0.019118 & gene1159 & Hypothetical protein & WP_042447906.1 \\
\hline AMUC_RS07530 & 0.682 & $4.59 \mathrm{E}-08$ & gene1496 & Phosphate/sulfate permease & WP_012420448.1 \\
\hline AMUC_RS09690 & 0.673 & $2.19 \mathrm{E}-23$ & gene1930 & Hypothetical protein & WP_012420848.1 \\
\hline AMUC_RS10910 & 0.662 & $3.96 \mathrm{E}-12$ & gene 2175 & PEP-CTERM domain protein & WP_012421069.1 \\
\hline AMUC_RS10505 & 0.660 & $5.80 \mathrm{E}-11$ & gene2095 & Hypothetical protein & WP_012420995.1 \\
\hline AMUC_RS07510 & 0.652 & $3.72 \mathrm{E}-07$ & gene1492 & Molecular chaperone DnaK & WP_012420444.1 \\
\hline AMUC_RS11765 & 0.648 & 0.000103 & gene410 & Hypothetical protein & WP_052294421.1 \\
\hline AMUC_RS09570 & 0.629 & 0.010839 & gene1906 & Hypothetical protein & WP_042448291.1 \\
\hline AMUC_RS07260 & 0.628 & $1.43 \mathrm{E}-06$ & gene1443 & Hypothetical protein & WP_042448027.1 \\
\hline AMUC_RS02540 & 0.620 & $3.91 \mathrm{E}-20$ & gene506 & PDZ/DHR/GLGF domain-containing protein & WP_012419514.1 \\
\hline AMUC_RS06360 & 0.616 & $9.94 \mathrm{E}-10$ & gene1266 & Holliday junction DNA helicase & WP_012420231.1 \\
\hline AMUC_RS00050 & 0.597 & $1.24 \mathrm{E}-17$ & gene9 & Pseudouridine synthase & WP_012419070.1 \\
\hline AMUC_RS01000 & 0.594 & $5.33 \mathrm{E}-17$ & gene198 & Hypothetical protein & WP_012419233.1 \\
\hline AMUC_RS10890 & 0.589 & $5.84 \mathrm{E}-21$ & gene2171 & Efflux RND transporter periplasmic adaptor subunit & WP_051729712.1 \\
\hline \multicolumn{6}{|l|}{ Downregulated genes } \\
\hline AMUC_RS00360 & -1.343 & $1.18 \mathrm{E}-10$ & gene72 & Membrane protein & WP_042448508.1 \\
\hline AMUC_RS00015 & -1.317 & $5.85 \mathrm{E}-44$ & gene2 & NUDIX hydrolase & WP_012419063.1 \\
\hline AMUC_RS07395 & -1.303 & $3.58 \mathrm{E}-27$ & gene 1470 & Short-chain dehydrogenase/reductase SDR & WP_012420428.1 \\
\hline AMUC_RS01355 & -1.225 & $5.07 \mathrm{E}-68$ & gene268 & Hypothetical protein & \\
\hline AMUC_RS06150 & -1.095 & $3.31 \mathrm{E}-08$ & gene 1224 & Potassium transporter KtrB & WP_012420193.1 \\
\hline AMUC_RS09840 & -1.084 & $2.88 \mathrm{E}-50$ & gene1961 & ECF subfamily RNA polymerase sigma- 24 subunit & WP_012420873.1 \\
\hline AMUC_RS01425 & -1.051 & $1.07 \mathrm{E}-31$ & gene282 & 3-Methyl-2-oxobutanoate hydroxymethyltransferase & WP_012419313.1 \\
\hline
\end{tabular}


Table 1 (continued)

\begin{tabular}{|c|c|c|c|c|c|}
\hline Locus_tag & $\begin{array}{l}\text { Log2 fold } \\
\text { change }\end{array}$ & padj & ID & Product & Protein_ID \\
\hline AMUC_RS01260 & -1.043 & $2.12 \mathrm{E}-25$ & gene249 & Hypothetical protein & WP_042447516.1 \\
\hline AMUC_RS09380 & -1.039 & $3.00 \mathrm{E}-79$ & gene1868 & Phosphocarrier protein $\mathrm{Hpr}$ & WP_012420789.1 \\
\hline AMUC_RS06145 & -1.017 & $1.45 \mathrm{E}-06$ & gene1223 & Potassium-transporting ATPase subunit B & WP_012420192.1 \\
\hline AMUC_RS02660 & -1.006 & $2.49 \mathrm{E}-23$ & gene530 & $50 \mathrm{~S}$ ribosomal protein $\mathrm{L} 21$ & WP_012419537.1 \\
\hline AMUC_RS06345 & -0.957 & $7.49 \mathrm{E}-26$ & gene1263 & 50S ribosomal protein $\mathrm{L} 28$ & WP_012420229.1 \\
\hline AMUC_RS08450 & -0.948 & $4.78 \mathrm{E}-22$ & gene1682 & Nucleoside-diphosphate kinase & WP_012420615.1 \\
\hline AMUC_RS09030 & -0.941 & $3.91 \mathrm{E}-22$ & gene1798 & Hypothetical protein & WP_042448236.1 \\
\hline AMUC_RS11295 & -0.932 & $2.99 \mathrm{E}-51$ & gene2253 & Threonine dehydrogenase & WP_012421139.1 \\
\hline AMUC_RS06355 & -0.926 & $3.22 \mathrm{E}-57$ & gene1265 & Alcohol dehydrogenase & WP_012420230.1 \\
\hline AMUC_RS02895 & -0.896 & $2.05 \mathrm{E}-24$ & gene577 & Glutamate 5-kinase & WP_012419582.1 \\
\hline AMUC_RS08820 & -0.894 & $2.28 \mathrm{E}-38$ & gene1756 & Phosphatidylserine decarboxylase & WP_012420686.1 \\
\hline AMUC_RS05935 & -0.861 & $1.41 \mathrm{E}-21$ & gene1181 & ATP phosphoribosyltransferase & WP_012420148.1 \\
\hline AMUC_RS09680 & -0.858 & $3.10 \mathrm{E}-11$ & gene1928 & Hypothetical protein & WP_042448307.1 \\
\hline AMUC_RS01595 & -0.836 & $6.37 \mathrm{E}-15$ & gene316 & Ribonuclease HIII & WP_042448620.1 \\
\hline AMUC_RS02580 & -0.834 & $1.11 \mathrm{E}-25$ & gene514 & N-Acetyltransferase GCN5 & WP_012419522.1 \\
\hline AMUC_RS03790 & -0.814 & $2.43 \mathrm{E}-17$ & gene755 & Beta-glucanase & WP_012419750.1 \\
\hline AMUC_RS06035 & -0.812 & $5.83 \mathrm{E}-13$ & gene1201 & Hypothetical protein & WP_012420169.1 \\
\hline AMUC_RS05250 & -0.807 & $7.34 \mathrm{E}-19$ & gene1048 & Hypothetical protein & WP_012420024.1 \\
\hline AMUC_RS06140 & -0.804 & $3.10 \mathrm{E}-07$ & gene1222 & Potassium-transporting ATPase subunit KdpA & WP_022196803.1 \\
\hline AMUC_RS05000 & -0.795 & $8.76 \mathrm{E}-10$ & gene998 & 50S ribosomal protein L5 & WP_012419973.1 \\
\hline AMUC_RS01360 & -0.793 & $5.73 \mathrm{E}-22$ & gene269 & tRNA (guanine(37)-N(1))-methyltransferase & WP_042448603.1 \\
\hline AMUC_RS04320 & -0.784 & 0.017267 & gene861 & Cupin & WP_012419849.1 \\
\hline AMUC_RS10155 & -0.779 & $6.39 \mathrm{E}-15$ & gene2026 & Nitrogen-fixing protein NifU & WP_012420930.1 \\
\hline AMUC_RS00740 & -0.779 & $7.93 \mathrm{E}-22$ & gene147 & Transposase & WP_012419186.1 \\
\hline AMUC_RS04995 & -0.769 & $4.30 \mathrm{E}-22$ & gene997 & 50 S ribosomal protein L24 & WP_012419972.1 \\
\hline AMUC_RS01750 & -0.746 & $5.21 \mathrm{E}-12$ & gene347 & $30 \mathrm{~S}$ ribosomal protein $\mathrm{S} 12$ & WP_012419365.1 \\
\hline AMUC_RS08815 & -0.744 & $4.18 \mathrm{E}-07$ & gene1755 & Secretion protein & WP_012420685.1 \\
\hline AMUC_RS02670 & -0.739 & $4.76 \mathrm{E}-12$ & gene532 & Transcriptional repressor & WP_012419539.1 \\
\hline AMUC_RS02010 & -0.735 & $1.06 \mathrm{E}-48$ & gene 400 & Hypothetical protein & WP_042447573.1 \\
\hline AMUC_RS05195 & -0.716 & $2.85 \mathrm{E}-13$ & gene1037 & Hypothetical protein & WP_051729423.1 \\
\hline AMUC_RS02675 & -0.716 & $3.12 \mathrm{E}-25$ & gene533 & Fe-S cluster assembly ATPase SufC & WP_035196050.1 \\
\hline AMUC_RS11880 & -0.704 & $1.29 \mathrm{E}-10$ & gene875 & Hypothetical protein & WP_052294442.1 \\
\hline AMUC_RS05795 & -0.701 & $1.23 \mathrm{E}-12$ & gene1153 & 23S rRNA (guanosine(2251)-2'-O)-methyltransferase RlmB & WP_012420121.1 \\
\hline AMUC_RS09135 & -0.692 & $2.57 \mathrm{E}-17$ & gene1819 & Recombinase RecQ & WP_012420743.1 \\
\hline AMUC_RS10835 & -0.683 & $1.69 \mathrm{E}-21$ & gene2160 & Dihydrofolate reductase & WP_012421055.1 \\
\hline AMUC_RS07650 & -0.661 & $6.98 \mathrm{E}-17$ & gene1521 & $50 \mathrm{~S}$ ribosomal protein $\mathrm{L} 31$ & WP_035196558.1 \\
\hline AMUC_RS06690 & -0.659 & $3.27 \mathrm{E}-15$ & gene1330 & GDP-mannose 4\%2C6-dehydratase & WP_012420289.1 \\
\hline AMUC_RS03920 & -0.658 & $2.58 \mathrm{E}-30$ & gene781 & GTP-binding protein & WP_012419774.1 \\
\hline AMUC_RS01615 & -0.655 & $3.21 \mathrm{E}-18$ & gene320 & Hypothetical protein & WP_012419341.1 \\
\hline AMUC_RS01735 & -0.655 & $2.19 \mathrm{E}-08$ & gene344 & $30 \mathrm{~S}$ ribosomal protein $\mathrm{S} 10$ & WP_012419362.1 \\
\hline AMUC_RS00220 & -0.654 & $1.37 \mathrm{E}-07$ & gene43 & N-Acetyltransferase GCN5 & WP_012419101.1 \\
\hline AMUC_RS06205 & -0.645 & $3.70 \mathrm{E}-11$ & gene1235 & Amino acid lyase & WP_012420202.1 \\
\hline AMUC_RS09155 & -0.644 & $1.09 \mathrm{E}-09$ & gene1823 & Succinyl-CoA ligase subunit beta & WP_012420746.1 \\
\hline AMUC_RS06540 & -0.644 & $6.88 \mathrm{E}-15$ & gene1301 & Hypothetical protein & WP_042447975.1 \\
\hline AMUC_RS05005 & -0.643 & $4.22 \mathrm{E}-16$ & gene999 & $30 \mathrm{~S}$ ribosomal protein $\mathrm{S} 8$ & WP_012419974.1 \\
\hline AMUC_RS02380 & -0.640 & $5.42 \mathrm{E}-19$ & gene474 & CinA-like protein & WP_012419483.1 \\
\hline AMUC_RS03785 & -0.638 & $4.04 \mathrm{E}-12$ & gene754 & Beta-glucanase & WP_012419749.1 \\
\hline AMUC_RS10055 & -0.635 & $9.20 \mathrm{E}-22$ & gene2005 & MBL fold metallo-hydrolase & WP_012420911.1 \\
\hline
\end{tabular}


Table 1 (continued)

\begin{tabular}{|c|c|c|c|c|c|}
\hline Locus_tag & $\begin{array}{l}\text { Log2 fold } \\
\text { change }\end{array}$ & padj & ID & Product & Protein_ID \\
\hline AMUC_RS05010 & -0.634 & 0.002924 & gene1000 & 50S ribosomal protein L6 & WP_012419975.1 \\
\hline AMUC_RS09395 & -0.632 & $5.24 \mathrm{E}-16$ & gene1871 & $\mathrm{ABC}$ transporter ATP-binding protein & WP_012420792.1 \\
\hline AMUC_RS05015 & -0.630 & $1.05 \mathrm{E}-06$ & gene1001 & 50S ribosomal protein $\mathrm{L} 18$ & WP_012419976.1 \\
\hline AMUC_RS09465 & -0.623 & $2.25 \mathrm{E}-31$ & gene1885 & Glycine-tRNA ligase & WP_012420806.1 \\
\hline AMUC_RS01435 & -0.623 & $1.77 \mathrm{E}-35$ & gene284 & 4-Hydroxy-tetrahydrodipicolinate reductase & WP_012419315.1 \\
\hline AMUC_RS01170 & -0.622 & $1.77 \mathrm{E}-18$ & gene231 & Glucose-1-phosphate thymidylyltransferase & WP_012419267.1 \\
\hline AMUC_RS11245 & -0.621 & $2.42 \mathrm{E}-16$ & gene2243 & Malate dehydrogenase & WP_012421129.1 \\
\hline AMUC_RS01745 & -0.620 & 0.010316 & gene346 & 30 S ribosomal protein $\mathrm{S} 7$ & WP_012419364.1 \\
\hline AMUC_RS01390 & -0.615 & $1.50 \mathrm{E}-07$ & gene275 & GNAT family acetyltransferase & WP_012419307.1 \\
\hline AMUC_RS04460 & -0.614 & $1.47 \mathrm{E}-13$ & gene889 & DNA-binding response regulator & WP_012419876.1 \\
\hline AMUC_RS11080 & -0.614 & $3.24 \mathrm{E}-11$ & gene 2210 & Hypothetical protein & WP_012421098.1 \\
\hline AMUC_RS07515 & -0.605 & 0.04402 & gene1493 & Molecular chaperone GroES & WP_012420445.1 \\
\hline AMUC_RS01690 & -0.604 & $1.05 \mathrm{E}-06$ & gene 335 & 50S ribosomal protein L16 & WP_012419353.1 \\
\hline AMUC_RS10500 & -0.604 & $7.83 \mathrm{E}-11$ & gene2094 & Thioredoxin & WP_012420994.1 \\
\hline AMUC_RS08060 & -0.602 & $1.20 \mathrm{E}-08$ & gene1603 & DNA-directed RNA polymerase subunit alpha & WP_012420541.1 \\
\hline AMUC_RS06385 & -0.599 & $1.46 \mathrm{E}-14$ & gene1271 & Hypothetical protein & WP_031930834.1 \\
\hline AMUC_RS10950 & -0.598 & $1.14 \mathrm{E}-19$ & gene2183 & Glutamate dehydrogenase & WP_012421075.1 \\
\hline AMUC_RS07810 & -0.597 & $3.84 \mathrm{E}-11$ & gene1553 & $\begin{array}{l}\text { Phosphoribosylformimino-5-aminoimidazole carboxamide } \\
\text { ribotide isomerase }\end{array}$ & WP_012420494.1 \\
\hline AMUC_RS09600 & -0.593 & $6.92 \mathrm{E}-05$ & gene1912 & $\mathrm{Fe}-\mathrm{S}$ center ferredoxin & WP_012420831.1 \\
\hline AMUC_RS01955 & -0.593 & $2.32 \mathrm{E}-10$ & gene389 & ATP-binding protein & WP_012419404.1 \\
\hline AMUC_RS08145 & -0.590 & $3.01 \mathrm{E}-18$ & gene 1620 & Type III restriction endonuclease subunit $\mathrm{R}$ & WP_012420558.1 \\
\hline AMUC RS03260 & -0.585 & $4.81 \mathrm{E}-10$ & gene 650 & Flavin reductase & WP_042448704.1 \\
\hline
\end{tabular}

Log2 fold change $=$ ox-bile/control condition $(n=3$; the experiment was performed in triplicate $)$

Padj was calculated using the procedure of Benjamini and Hochberg. The upregulated and downregulated genes under ox-bile condition $(p a d j<0.05$, $\log 2$ fold changes with cut-off at $<-0.585$ and $>0.585$ ) were listed

upregulated ( adj $<0.05, \log 2$ fold change $=0.211,0.270$, 0.260 , and 0.210 , Supplementary Table S1). The gene expression of bile acid:sodium symporter (Amuc_0139) was not found to be significantly different in these conditions.
Fig. 5 Gene clusters up- and downregulated under ox-bile condition. The orange and blue arrows show the up- and downregulated gene clusters, respectively
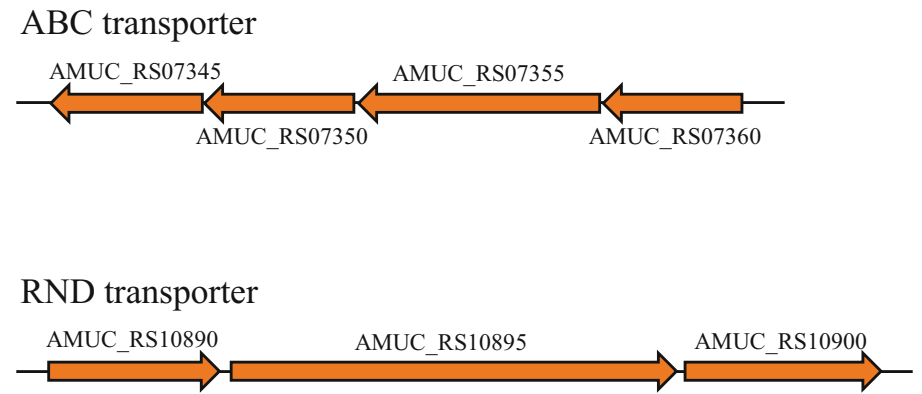

Potassium transporter

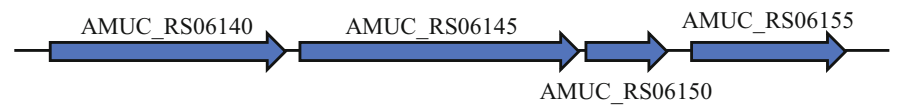

$1000 \mathrm{bp}$ 
Furthermore, 77 genes were downregulated in the presence of ox-bile. In contrast to the upregulation of $\mathrm{ABC}$ transporters, the potassium transport system (AMUC_RS06145 and AMUC_RS06150) was significantly downregulated. Neighboring genes (AMUC RS06140 encoding potassiumtransporting ATPase subunit KdpA and AMUC_RS06155 encoding osmosensitive $\mathrm{K}$ channel His kinase sensor), part of the gene cluster of the potassium transport system, were also slightly downregulated ( $p$ adj $<0.05,-0.804$, and -0.453 fold change, respectively). Some enzymes belonging to dehydrogenase, hydrogenase, decarboxylase, ligase, and reductase were also downregulated (Table 1). Although the stress protein DnaK gene was upregulated, the GroES gene was downregulated by ox-bile. In addition, the gene encoding short-chain dehydrogenase/reductase SDR (AMUC_RS07395), which is a member of steroid degradation enzymes (Ji et al. 2014), was downregulated under ox-bile condition.

\section{The effect of membrane transporter inhibitor on ox- bile tolerance}

Transcriptome analysis showed the gene expression of HlyD$\mathrm{ABC}$ and RND type transporters was upregulated under oxbile condition. To investigate whether these transporters are related to bile acid tolerance in $A$. muciniphila, an inhibitor test using orthovanadate and PA $\beta N$ (Phe-Arg $\beta$-naphthylamide dihydrochloride) was performed. Although orthovanadate inhibited the growth of A. muciniphila under control condition, the highest inhibition was observed under ox-bile with orthovanadate condition (Fig. 6a). In addition, PA $\beta N$, which is an RND efflux pump inhibitor, also reduced the ox-bile tolerance of A. muciniphila (Fig. 6b).

\section{Discussion}

Bile acids can affect the microbial composition in the gut (Wahlstrom et al. 2016). A. muciniphila is an interesting gut bacterium correlated with host health. Herein, the growth and change in gene expression of A. muciniphila in response to bile acids were investigated. All tested bile extracts except for bile extract from porcine inhibited the growth of $A$. muciniphila (Fig. 1). The difference in the phospholipid and the hydroxylation of glycine and tauroconjugate composition between bovine and porcine bile was reported (Coleman et al. 1979; Farthing et al. 1985). A different bile acid or phospholipid composition may cause a non-inhibitory effect of bile extract from porcine although the difference of this mechanism is not known. Primary bile acids such as CA, GCA, and GCDCA showed an inhibitory effect against $A$. muciniphila (Fig. 2). Interestingly, this study also showed the increased growth of A. muciniphila cultured with secondary bile acid DCA (Fig. 2) or a low concentration of bile salts

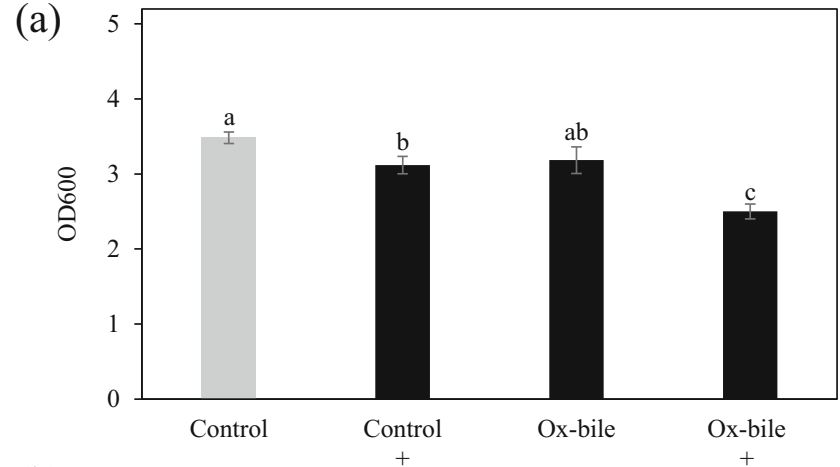

(b)

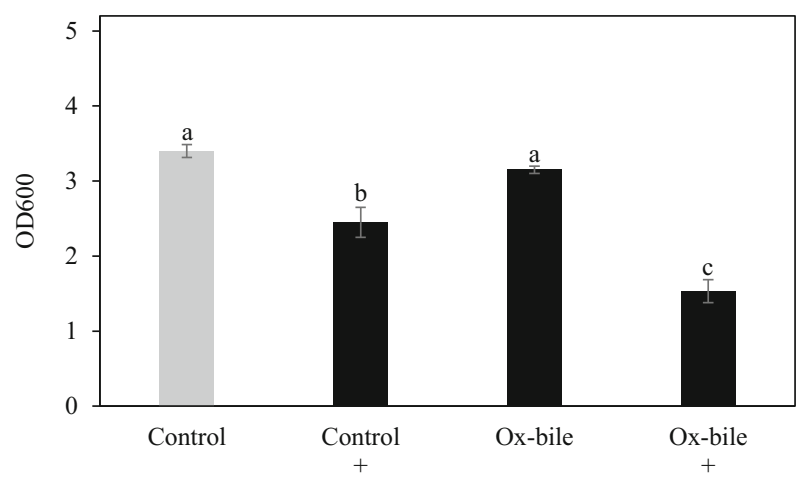

Fig. 6 The effect of transporter inhibitor on the tolerance of $A$. muciniphila against ox-bile. A. muciniphila was cultured in medium containing $0.1 \%$ ox-bile supplemented with or without $4 \mathrm{mM}$ orthovanadate (a) or $5 \mu \mathrm{g} / \mathrm{mL} \mathrm{Pa} \beta \mathrm{N}$ (b). After incubation at $37^{\circ} \mathrm{C}$ for $48 \mathrm{~h}$, the optical density was measured $\left(\mathrm{OD}_{600}\right)$. These experiments were performed in triplicate $(n=3)$. Control means no treatment with ox-bile. ${ }^{+}$Treatment with an inhibitor. Different letters denote significant differences (Tukey's HSD test, $p<0.05$ )

mixture (Sigma) consisting of CA and DCA (in a ratio of 1:1) (Fig. 1). On the other hand, a high concentration of bile salts mixture strongly inhibited the growth of A. muciniphila (Fig. 1). Our previous review showed that A. muciniphila is abundantly present in the large intestine (Geerlings et al. 2018), where primary bile acids can be converted to secondary bile acids (Foley et al. 2019). The concentration of CA or ratio of DCA to CA may affect the growth of A. muciniphila in the gut. Another report demonstrated that DCA-induced MUC2 protein expression of human colon carcinoma cells leads to mucin production which is a carbon source of A. muciniphila (Song et al. 2005). These results indicate that DCA is considered to be an important factor for A. muciniphila to persist in the gut. Several genera such as Rhodococcus and Mycobacterium have meta-cleavage dioxygenases to degrade DCA (Merino et al. 2013). However, no gene encoding a meta-cleavage dioxygenase was observed in the genome of A. muciniphila. Ursodeoxycholic acid could also increase the cell number of A. muciniphila in mice (Van den Bossche et al. 2017). Another report showed that the increase of bile acids (especially, cholic acid) could reduce the population of $A$. muciniphila in mice (Zheng et al. 2017). These results implied 
that a balance of bile acids plays an important role for the growth of A. muciniphila in the gut. Additional experiments are needed to clarify the relationship between secondary bile acids and the metabolism of A. muciniphila.

Squalene synthase inhibitor ZA inhibited the growth of $A$. muciniphila in the presence of bile extracts and mixture (Fig. 3). Squalene is the precursor of hopanoid which is required for bile acid tolerance and other stress conditions in Rhodopseudomonas palustris (Welander et al. 2009). This report indicated that a lack of hopanoids results in increased membrane permeability and could decrease bile acid tolerance. Transcriptome analysis also showed that terpene cyclase/ mutase family proteins (AMUC_RS03775, AMUC_RS06010, AMUC_RS06015, and AMUC_RS03775), which are considered to be associated with hopanoid production, were upregulated in the presence of ox-bile. These results indicate that hopanoid production associated with membrane permeability could contribute to bile acid tolerance in A. muciniphila.

The mechanism in stress response to bile acids was investigated by analyzing the transcriptional response of A. muciniphila in the presence of ox-bile. A gene cluster of the $\mathrm{ABC}$ transporter system shown in Fig. 5 was significantly upregulated. ABC transporters are divided into several groups with different characteristics associated with the uptake of nutrients and export of drugs (Locher 2016). ABC transporter BmrAB, comprising of 652- and 671-amino acid proteins, is required for bile acid tolerance in Bifidobacterium longum BBMN68 (Xu et al. 2019). The amino acid sequence of BmrA (652 aa, BBMN68_1797) in B. longum is similar to the $\mathrm{ABC}$ transporter ATP-binding protein AMUC_RS00905 (34\% identity; 54\% similarity, 594 aa). BmrB (671 aa, BBMN68_1798) is similar with ABC transporter ATPbinding protein AMUC_RS00910 (47\% identity; 64\% similarity, $616 \mathrm{aa})$. Their genes are different in comparison to the upregulated $\mathrm{ABC}$ transporter genes in Fig. 5. In addition, the $\mathrm{ABC}$ transporter gene cluster of $A$. muciniphila contains the gene for HlyD (AMUC_RS07360) known as a periplasmic adaptor protein (Symmons et al. 2015). A. muciniphila may use ABC-type multidrug transport systems different from Bifidobacterium to improve the tolerance to bile acids. A gene encoding an efflux RND transporter periplasmic adaptor subunit (AMUC_RS10890) and a gene encoding an efflux RND transporter permease subunit (AMUC_RS10895) were also upregulated in the presence of ox-bile. RND (resistance-nodulation-division) is known as a part of a transporter system (Symmons et al. 2015). RND transporters as well as ABC transporters are considered to be bile acid response genes in Campylobacterales (Okoli et al. 2007). These results imply that both types of transporter systems (RND and ABC) may be bile response genes required for bile acid tolerance in A. muciniphila.

Both membrane transporter (ABC and RND type) inhibitory tests using orthovanadate and $\mathrm{PA} \beta \mathrm{N}$ supported the transcriptome analysis (Fig. 6). These transporter inhibitors were also used for inhibitory test of transporters in an obligately anaerobic gut bacteria Bacteroides fragilis (Ricci and Piddock 2003). Alternatively, these inhibitors also slightly reduced the growth of A. muciniphila under the control condition. Orthovanadate might inhibit other $\mathrm{ABC}$ transporters required for growth or cause a oxidative stress (Minasi and Willsky 1991; Schneider and Hunke 1998). PA $\beta N$ also might inhibit an efflux pump required for growth or cause a weak membrane-destabilization although it is known as an efflux pump inhibitor used for bile tolerance tests (Lin and Martinez 2006; Misra et al. 2015; Sannasiddappa et al. 2015) as well as antibiotic resistance tests (Chitsaz et al. 2019). However, transporters could be strongly related to bile acid tolerance in A. muciniphila because the addition of transporter inhibitor showed the strongest growth inhibition under bile acid condition. Alternatively, transporter inhibitors, which are originally developed as an inhibition of antibiotic resistance bacteria (Shriram et al. 2018), strongly inhibited the growth of $A$. muciniphila under bile acid condition. These results imply that the impact of transporter inhibitors on commensal gut microbiota such as A. muciniphila is needed for our health.

Upregulation of the gene encoding a PEP-CTERM domain protein (AMUC_RS10910) was also observed. This protein is related to exopolysaccharide biosynthesis (Haft et al. 2006). Other exopolysaccharide-associated genes (Supplemental Table S1) and the gene for capsular polysaccharide biosynthesis protein (AMUC_RS07555, AMUC_RS11095) and polysaccharide export protein (AMUC_RS07560) were slightly but significantly downregulated $(\log 2$ fold change $=-0.142$, 0.217 , and -0.258 , respectively). In contrast, the gene for polysaccharide deacetylase (AMUC_RS08035), which is associated with the hydrolysis of either the $\mathrm{N}$-linked acetyl group from GlcNAc or $O$-linked acetyl groups from $O$-acetylxylose residues (Balomenou et al. 2013), was significantly upregulated ( $\log 2$ fold change $=0.237$ ). These results imply that EPS (exopolysaccharides) modification leading to a change in membrane composition rather than biosynthesis could occur in response to ox-bile and contribute to bile acid tolerance.

On the other hand, a gene cluster containing a potassium transporter was significantly downregulated in the presence of ox-bile. Potassium ions are abundant inside the cells and regulated by the external $\mathrm{K}^{+}$concentration (Kuo et al. 2005). The $\mathrm{K}^{+}$transport operon is upregulated by $\mathrm{K}^{+}$limitation and high osmolarity and downregulated by high concentration of $\mathrm{K}+$ in Salmonella typhimurium (Frymier et al. 1997). Membrane stress or disturbance of potassium balance caused by oxbile-associated membrane damage may lead to downregulation of a $\mathrm{K}^{+}$transporter. In addition, the genes for a membrane protein (AMUC RS00360), NUDIX hydrolase (AMUC_RS00015), and short-chain dehydrogenase/ reductase SDR (AMUC_RS07395) were the top 3 highly downregulated genes under ox-bile condition (Table 1). One of the short-chain dehydrogenase/reductase (SDR) is known as $7 \alpha$-hydroxysteroid dehydrogenase with a N-terminal Gly- 


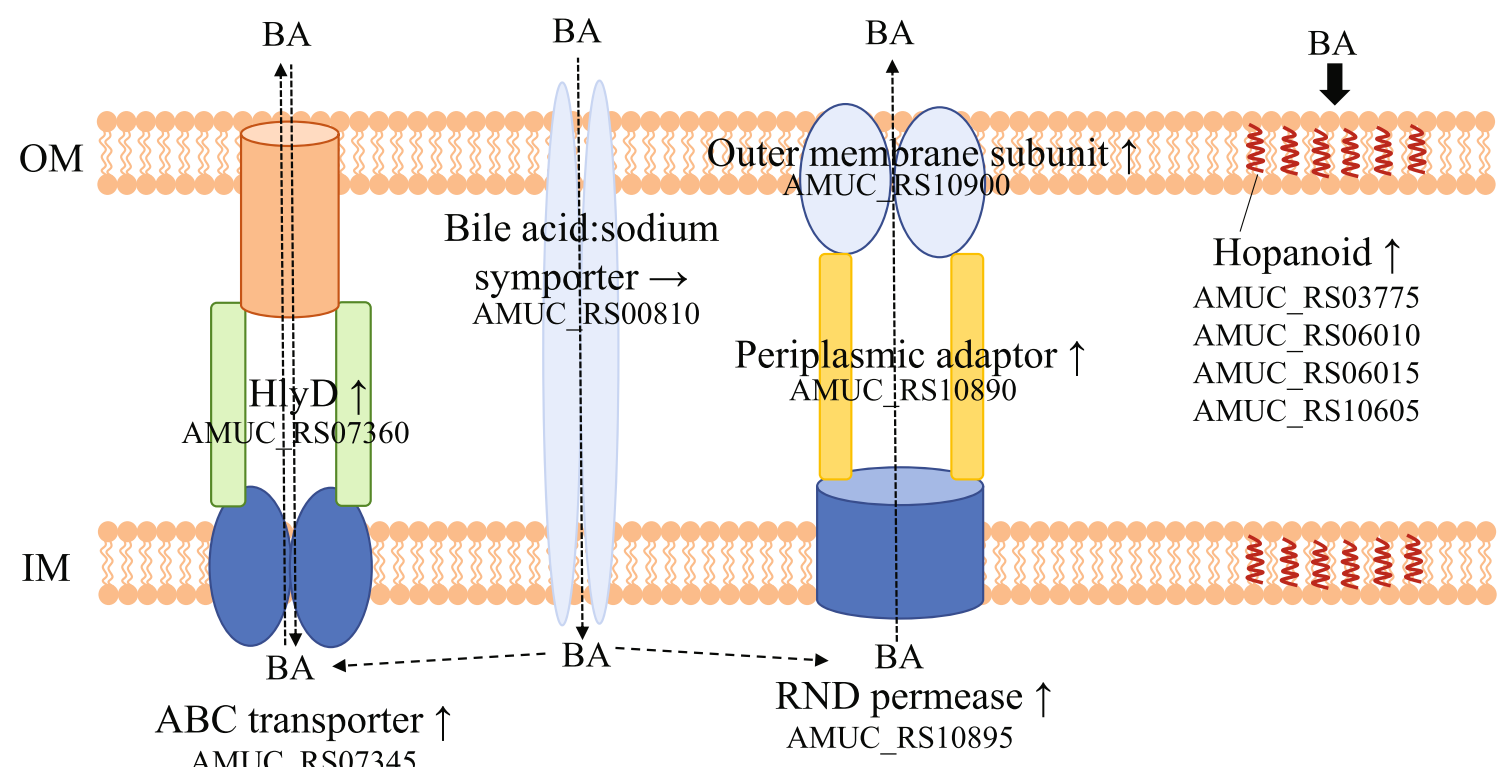

AMUC RS07345

AMUC RS07350

AMUC_RS07355

Fig. 7 Putative bile acid response system in A. muciniphila. After an ox-bile exposure, the expression level of genes encoding $\mathrm{ABC}$ transporter (AMUC RS07345 to AMUC_RS07360), RND type transporter (AMUC_RS10890 to AMUC_RS10900), and hopanoid biosynthesis (AMUC_RS03775, AMUC_RS06010, AMUC_RS06015, and AMUC_RS10605) was upregulated. The inhibitors against transporters and hopanoid biosynthesis reduced

the tolerance against ox-bile. The change in membrane transporters and membrane composition caused by hopanoid production could contribute to bile tolerance in A. muciniphila like other bacteria. No change in gene expression of AMUC RS00810 encoding bile acid:sodium symporter was observed. Bile acid (BA), $\uparrow$ upregulated gene, $\downarrow$ downregulated gene, $\rightarrow$ no change in gene expression

X-X-X-Gly-X-Gly and a Tyr-X-X-X-Lys segment, which may be related to steroid degradation such as bile acid (Ji et al. 2014). This result implies there may be bile acid metabolism using SDR in A. muciniphila after transport of bile acids like in Bifidobacterium and Clostridium with a $7 \alpha / 7 \beta$ dehydroxylation pathway (Ridlon et al. 2016).

Our results suggest that membrane-associated molecules such as isoprenoids (squalene and hopanoids) and transporters could be important factors in bile acid tolerance (Fig. 7). The change in membrane composition caused by hopanoid production could protect cell membrane from bile acids. In addition, although no change in gene expression of AMUC_RS00810 encoding bile acid:sodium symporter was observed, this symporter and other transporter systems (ABC and RND type) may contribute to transport of bile acids and its metabolism like in other bacteria (Lin et al. 2003; Locher 2016; Ruiz et al. 2013). Further characterization on a phenotypic level will help us understand the bile acid response mechanism of $A$. muciniphila. The change in gene expression and physiology of $A$. muciniphila in response to bile acids can provide novel information on bacterial persistence in the gut. Modulation of secondary bile acids could be a novel target for increasing the growth of A. muciniphila in the gut and preventing metabolic syndrome and gut disease.

Acknowledgments We are grateful to Janneke Elzinga, Patrick Schimmel, Ioannis Kostopoulos, and Steven Aalvink for the help with a part of the experiment.

Authors' contributions T.H. designed and performed experiments, analyzed and interpreted results, generated figures and tables, and conceived the manuscript. S.G. supported a part of the experiment. B.N. analyzed transcriptomics data. C.B. conceived and supervised the project and contributed to the writing of the manuscript.

Funding The work was supported by a long-term foreign residency research program in NARO, Japan.

Data availability A. muciniphila used in this study is MucT (DSM 22959).

\section{Compliance with ethical standards}

Competing interests The authors declare that they have no competing interests.

Ethics approval and consent to participate This article does not contain any studies concerned with experimentation on human or animals.

Open Access This article is licensed under a Creative Commons Attribution 4.0 International License, which permits use, sharing, adaptation, distribution and reproduction in any medium or format, as long as you give appropriate credit to the original author(s) and the source, provide a link to the Creative Commons licence, and indicate if changes were made. The images or other third party material in this article are included in the article's Creative Commons licence, unless indicated otherwise in a credit line to the material. If material is not included in the article's Creative Commons licence and your intended use is not permitted by statutory regulation or exceeds the permitted use, you will need to obtain permission directly from the copyright holder. To view a copy of this licence, visit http://creativecommons.org/licenses/by/4.0/. 


\section{References}

Ansaldo E, Slayden LC, Ching KL, Koch MA, Wolf NK, Plichta DR, Brown EM, Graham DB, Xavier RJ, Moon JJ, Barton GM (2019) Akkermansia muciniphila induces intestinal adaptive immune responses during homeostasis. Science 364(6446):1179-1184. https://doi.org/10.1126/science.aaw7479

Balomenou S, Fouet A, Tzanodaskalaki M, Couture-Tosi E, Bouriotis V, Boneca IG (2013) Distinct functions of polysaccharide deacetylases in cell shape, neutral polysaccharide synthesis and virulence of Bacillus anthracis. Mol Microbiol 87(4):867-883. https://doi.org/ 10.1111/mmi.12137

Begley M, Gahan CG, Hill C (2002) Bile stress response in Listeria monocytogenes LO28: adaptation, cross-protection, and identification of genetic loci involved in bile resistance. Appl Environ Microbiol 68(12):6005-6012. https://doi.org/10.1128/aem.68.12. 6005-6012.2002

Bray NL, Pimentel H, Melsted P, Pachter L (2016) Near-optimal probabilistic RNA-seq quantification. Nat Biotechnol 34(5):525-527. https://doi.org/10.1038/nbt.3519

Bron PA, Marco M, Hoffer SM, Van Mullekom E, de Vos WM, Kleerebezem M (2004) Genetic characterization of the bile salt response in Lactobacillus plantarum and analysis of responsive promoters in vitro and in situ in the gastrointestinal tract. J Bacteriol 186(23):7829-7835. https://doi.org/10.1128/jb.186.23.7829-7835. 2004

Bufe T, Hennig A, Klumpp J, Weiss A, Nieselt K, Schmidt H (2019) Differential transcriptome analysis of enterohemorrhagic Escherichia coli strains reveals differences in response to plantderived compounds. BMC Microbiol 19(1):212. https://doi.org/10. 1186/s12866-019-1578-4

Chen S, Zhou Y, Chen Y, Gu J (2018) fastp: an ultra-fast all-in-one FASTQ preprocessor. Bioinformatics 34(17):i884-i890. https:// doi.org/10.1093/bioinformatics/bty560

Chitsaz M, Booth L, Blyth MT, O'Mara ML, Brown MH (2019) Multidrug resistance in Neisseria gonorrhoeae: identification of functionally important residues in the MtrD efflux protein. $\mathrm{mBio}$ 10(6):e02277-e02219. https://doi.org/10.1128/mBio.02277-19

Coleman R, Iqbal S, Godfrey PP, Billington D (1979) Membranes and bile formation. Composition of several mammalian biles and their membrane-damaging properties. Biochem J 178(1):201-208. https://doi.org/10.1042/bj1780201

Consortium HMP (2012) Structure, function and diversity of the healthy human microbiome. Nature 486(7402):207-214. https://doi.org/10. 1038/nature11234

Derrien M, Vaughan EE, Plugge CM, de Vos WM (2004) Akkermansia muciniphila gen. nov., sp. nov., a human intestinal mucin-degrading bacterium. Int J Syst Evol Microbiol 54(Pt 5):1469-1476. https:// doi.org/10.1099/ijs.0.02873-0

Everard A, Belzer C, Geurts L, Ouwerkerk JP, Druart C, Bindels LB, Guiot Y, Derrien M, Muccioli GG, Delzenne NM, de Vos WM, Cani PD (2013) Cross-talk between Akkermansia muciniphila and intestinal epithelium controls diet-induced obesity. Proc Natl Acad Sci U S A 110(22):9066-9071. https://doi.org/10.1073/pnas. 1219451110

Farthing MJ, Keusch GT, Carey MC (1985) Effects of bile and bile salts on growth and membrane lipid uptake by Giardia lamblia. Possible implications for pathogenesis of intestinal disease. J Clin Invest 76(5):1727-1732. https://doi.org/10.1172/jci112162

Flint HJ, Scott KP, Louis P, Duncan SH (2012) The role of the gut microbiota in nutrition and health. Nat Rev Gastroenterol Hepatol 9(10):577-589. https://doi.org/10.1038/nrgastro.2012.156

Foley MH, O'Flaherty S, Barrangou R, Theriot CM (2019) Bile salt hydrolases: gatekeepers of bile acid metabolism and host- microbiome crosstalk in the gastrointestinal tract. PLoS Pathog 15(3):e1007581. https://doi.org/10.1371/journal.ppat.1007581

Frymier JS, Reed TD, Fletcher SA, Csonka LN (1997) Characterization of transcriptional regulation of the $k d p$ operon of Salmonella typhimurium. J Bacteriol 179(9):3061-3063. https://doi.org/10. 1128/jb.179.9.3061-3063.1997

Geerlings SY, Kostopoulos I, de Vos WM, Belzer C (2018) Akkermansia muciniphila in the human gastrointestinal tract: when, where, and how? Microorganisms 6(3):75. https://doi.org/10.3390/ microorganisms6030075

Haft DH, Paulsen IT, Ward N, Selengut JD (2006) Exopolysaccharideassociated protein sorting in environmental organisms: the PEPCTERM/EpsH system. Application of a novel phylogenetic profiling heuristic. BMC Biol 4:29. https://doi.org/10.1186/1741-7007-429

Hagi T, Kobayashi M, Kawamoto S, Shima J, Nomura M (2013) Expression of novel carotenoid biosynthesis genes from Enterococcus gilvus improves the multistress tolerance of Lactococcus lactis. J Appl Microbiol 114(6):1763-1771. https:// doi.org/10.1111/jam.12182

Hamon E, Horvatovich P, Bisch M, Bringel F, Marchioni E, AoudeWerner D, Ennahar S (2012) Investigation of biomarkers of bile tolerance in Lactobacillus casei using comparative proteomics. J Proteome Res 11(1):109-118. https://doi.org/10.1021/pr200828t

Hu PL, Yuan YH, Yue TL, Guo CF (2018) Bile acid patterns in commercially available oxgall powders used for the evaluation of the bile tolerance ability of potential probiotics. PLoS One 13(3): e0192964. https://doi.org/10.1371/journal.pone.0192964

Ji W, Chen Y, Zhang H, Zhang X, Li Z, Yu Y (2014) Cloning, expression and characterization of a putative 7alpha-hydroxysteroid dehydrogenase in Comamonas testosteroni. Microbiol Res 169(2-3):148154. https://doi.org/10.1016/j.micres.2013.07.009

Kuo MM, Haynes WJ, Loukin SH, Kung C, Saimi Y (2005) Prokaryotic $\mathrm{K}(+)$ channels: from crystal structures to diversity. FEMS Microbiol Rev 29(5):961-985. https://doi.org/10.1016/j.femsre.2005.03.003

Kurdi P, Kawanishi K, Mizutani K, Yokota A (2006) Mechanism of growth inhibition by free bile acids in lactobacilli and bifidobacteria. J Bacteriol 188(5):1979-1986. https://doi.org/10.1128/jb.188.5. 1979-1986.2006

LaRossa RA, Van Dyk TK (1991) Physiological roles of the DnaK and GroE stress proteins: catalysts of protein folding or macromolecular sponges? Mol Microbiol 5(3):529-534. https://doi.org/10.1111/j. 1365-2958.1991.tb00724.x

Lin J, Martinez A (2006) Effect of efflux pump inhibitors on bile resistance and in vivo colonization of Campylobacter jejuni. J Antimicrob Chemother 58(5):966-972. https://doi.org/10.1093/jac/ $\mathrm{dk1} 374$

Lin J, Sahin O, Michel LO, Zhang Q (2003) Critical role of multidrug efflux pump CmeABC in bile resistance and in vivo colonization of Campylobacter jejuni. Infect Immun 71(8):4250-4259. https://doi. org/10.1128/iai.71.8.4250-4259.2003

Locher KP (2016) Mechanistic diversity in ATP-binding cassette (ABC) transporters. Nat Struct Mol Biol 23(6):487-493. https://doi.org/10. 1038/nsmb.3216

Love MI, Huber W, Anders S (2014) Moderated estimation of fold change and dispersion for RNA-seq data with DESeq2. Genome Biol 15(12):550. https://doi.org/10.1186/s13059-014-0550-8

Merino E, Barrientos A, Rodriguez J, Naharro G, Luengo JM, Olivera ER (2013) Isolation of cholesterol- and deoxycholate-degrading bacteria from soil samples: evidence of a common pathway. Appl Microbiol Biotechnol 97(2):891-904. https://doi.org/10.1007/ s00253-012-3966-7

Minasi LA, Willsky GR (1991) Characterization of vanadate-dependent NADH oxidation stimulated by Saccharomyces cerevisiae plasma membranes. J Bacteriol 173(2):834-841. https://doi.org/10.1128/jb. 173.2.834-841.1991 
Misra R, Morrison KD, Cho HJ, Khuu T (2015) Importance of real-time assays to distinguish multidrug efflux pump-inhibiting and outer membrane-destabilizing activities in Escherichia coli. J Bacteriol 197(15):2479-2488. https://doi.org/10.1128/jb.02456-14

Okoli AS, Wadstrom T, Mendz GL (2007) MiniReview: bioinformatic study of bile responses in Campylobacterales. FEMS Immunol Med Microbiol 49(1):101-123. https://doi.org/10.1111/j.1574-695X. 2006.00194.x

Ouwerkerk JP, van der Ark KCH, Davids M, Claassens NJ, Finestra TR, de Vos WM, Belzer C (2016) Adaptation of Akkermansia muciniphila to the oxic-anoxic interface of the mucus layer. Appl Environ Microbiol 82(23):6983-6993. https://doi.org/10.1128/aem. 01641-16

Ricci V, Piddock L (2003) Accumulation of garenoxacin by Bacteroides fragilis compared with that of five fluoroquinolones. J Antimicrob Chemother 52(4):605-609. https://doi.org/10.1093/jac/dkg418

Ridlon JM, Harris SC, Bhowmik S, Kang DJ, Hylemon PB (2016) Consequences of bile salt biotransformations by intestinal bacteria. Gut Microbes 7(1):22-39. https://doi.org/10.1080/19490976.2015. 1127483

Rivas-Marin E, Stettner S, Gottshall EY, Santana-Molina C, Helling M, Basile F, Ward NL, Devos DP (2019) Essentiality of sterol synthesis genes in the planctomycete bacterium Gemmata obscuriglobus. Nat Commun 10(1):2916. https://doi.org/10.1038/s41467-019-10983-7

Rowland I, Gibson G, Heinken A, Scott K, Swann J, Thiele I, Tuohy K (2018) Gut microbiota functions: metabolism of nutrients and other food components. Eur J Nutr 57(1):1-24. https://doi.org/10.1007/ s00394-017-1445-8

Ruiz L, Margolles A, Sanchez B (2013) Bile resistance mechanisms in Lactobacillus and Bifidobacterium. Front Microbiol 4:396. https:// doi.org/10.3389/fmicb.2013.00396

Sannasiddappa TH, Hood GA, Hanson KJ, Costabile A, Gibson GR, Clarke SR (2015) Staphylococcus aureus MnhF mediates cholate efflux and facilitates survival under human colonic conditions. Infect Immun 83(6):2350-2357. https://doi.org/10.1128/iai.0023815

Saracut C, Molnar C, Russu C, Todoran N, Vlase L, Turdean S, Voidazan S, Copotoiu C (2015) Secondary bile acids effects in colon pathology. Experimental mice study. Acta Cir Bras 30(9):624-631. https:// doi.org/10.1590/s0102-865020150090000007

Schneider E, Hunke S (1998) ATP-binding-cassette (ABC) transport systems: functional and structural aspects of the ATP-hydrolyzing subunits/domains. FEMS Microbiol Rev 22(1):1-20. https://doi.org/10. 1111/j.1574-6976.1998.tb00358.x

Shriram V, Khare T, Bhagwat R, Shukla R, Kumar V (2018) Inhibiting bacterial drug efflux pumps via phyto-therapeutics to combat threatening antimicrobial resistance. Front Microbiol 9:2990. https://doi. org/10.3389/fmicb.2018.02990

Sicard JF, Le Bihan G, Vogeleer P, Jacques M, Harel J (2017) Interactions of intestinal bacteria with components of the intestinal mucus. Front Cell Infect Microbiol 7:387. https://doi.org/10.3389/ fcimb.2017.00387

Silipo A, Vitiello G, Gully D, Sturiale L, Chaintreuil C, Fardoux J, Gargani D, Lee HI, Kulkarni G, Busset N, Marchetti R, Palmigiano A, Moll H, Engel R, Lanzetta R, Paduano L, Parrilli M, Chang WS, Holst O, Newman DK, Garozzo D, D'Errico G, Giraud E, Molinaro A (2014) Covalently linked hopanoid-lipid a improves outer-membrane resistance of a Bradyrhizobium symbiont of legumes. Nat Commun 5:5106. https://doi.org/10.1038/ ncomms 6106

Sinha SR, Haileselassie Y, Nguyen LP, Tropini C, Wang M, Becker LS, Sim D, Jarr K, Spear ET, Singh G, Namkoong H, Bittinger K, Fischbach MA, Sonnenburg JL, Habtezion A (2020) Dysbiosisinduced secondary bile acid deficiency promotes intestinal inflammation. Cell Host Microbe 27(4):659-670.e5. https://doi.org/10. 1016/j.chom.2020.01.021
Soneson C, Love MI, Robinson MD (2015) Differential analyses for RNA-seq: transcript-level estimates improve gene-level inferences. F1000Res 4:1521. https://doi.org/10.12688/f1000research.7563.2

Song S, Byrd JC, Koo JS, Bresalier RS (2005) Bile acids induce MUC2 overexpression in human colon carcinoma cells. Cancer 103(8): 1606-1614. https://doi.org/10.1002/cncr.21015

Staley C, Weingarden AR, Khoruts A, Sadowsky MJ (2017) Interaction of gut microbiota with bile acid metabolism and its influence on disease states. Appl Microbiol Biotechnol 101(1):47-64. https:// doi.org/10.1007/s00253-016-8006-6

Studer N, Desharnais L, Beutler M, Brugiroux S, Terrazos MA, Menin L, Schurch CM, McCoy KD, Kuehne SA, Minton NP, Stecher B, Bernier-Latmani R, Hapfelmeier S (2016) Functional intestinal bile acid 7alpha-dehydroxylation by Clostridium scindens associated with protection from Clostridium difficile infection in a gnotobiotic mouse model. Front Cell Infect Microbiol 6:191. https://doi.org/10. 3389/fcimb.2016.00191

Symmons MF, Marshall RL, Bavro VN (2015) Architecture and roles of periplasmic adaptor proteins in tripartite efflux assemblies. Front Microbiol 6:513. https://doi.org/10.3389/fmicb.2015.00513

Thaiss CA, Zmora N, Levy M, Elinav E (2016) The microbiome and innate immunity. Nature 535(7610):65-74. https://doi.org/10. 1038/nature 18847

Van den Bossche L, Hindryckx P, Devisscher L, Devriese S, Van Welden S, Holvoet T, Vilchez-Vargas R, Vital M, Pieper DH, Vanden Bussche J, Vanhaecke L, Van de Wiele T, De Vos M, Laukens D (2017) Ursodeoxycholic acid and its taurine- or glycine-conjugated species reduce colitogenic dysbiosis and equally suppress experimental colitis in mice. Appl Environ Microbiol 83(7):e02766e02716. https://doi.org/10.1128/aem.02766-16

van der Ark KCH, Nugroho ADW, Berton-Carabin C, Wang C, Belzer C, de Vos WM, Schroen K (2017) Encapsulation of the therapeutic microbe Akkermansia muciniphila in a double emulsion enhances survival in simulated gastric conditions. Food Res Int 102:372-379. https://doi.org/10.1016/j.foodres.2017.09.004

van der Ark KCH, Aalvink S, Suarez-Diez M, Schaap PJ, de Vos WM, Belzer C (2018) Model-driven design of a minimal medium for Akkermansia muciniphila confirms mucus adaptation. Microb Biotechnol 11(3):476-485. https://doi.org/10.1111/1751-7915. 13033

Vital M, Rud T, Rath S, Pieper DH, Schluter D (2019) Diversity of bacteria exhibiting bile acid-inducible 7alpha-dehydroxylation genes in the human gut. Comput Struct Biotechnol J 17:10161019. https://doi.org/10.1016/j.csbj.2019.07.012

Wahlstrom A, Sayin SI, Marschall HU, Backhed F (2016) Intestinal crosstalk between bile acids and microbiota and its impact on host metabolism. Cell Metab 24(1):41-50. https://doi.org/10.1016/j. cmet.2016.05.005

Welander PV, Hunter RC, Zhang L, Sessions AL, Summons RE, Newman DK (2009) Hopanoids play a role in membrane integrity and $\mathrm{pH}$ homeostasis in Rhodopseudomonas palustris TIE-1. J Bacteriol 191(19):6145-6156. https://doi.org/10.1128/jb.00460-09

Xu Q, Zhai Z, An H, Yang Y, Yin J, Wang G, Ren F, Hao Y (2019) The MarR family regulator BmrR is involved in bile tolerance of Bifidobacterium longum BBMN68 via controlling the expression of an ABC transporter. Appl Environ Microbiol 85(3):e02453e02418. https://doi.org/10.1128/aem.02453-18

Zheng X, Huang F, Zhao A, Lei S, Zhang Y, Xie G, Chen T, Qu C, Rajani C, Dong B, Li D, Jia W (2017) Bile acid is a significant host factor shaping the gut microbiome of diet-induced obese mice. BMC Biol 15(1):120. https://doi.org/10.1186/s12915-017-0462-7

Publisher's note Springer Nature remains neutral with regard to jurisdictional claims in published maps and institutional affiliations. 